\title{
The mechanisms and mechanics of the toughening of epoxy polymers modified with silica nanoparticles
}

T.H. Hsieh, A.J. Kinloch*, K. Masania, A.C. Taylor

Department of Mechanical Engineering, Imperial College London, South Kensington Campus, London SW7 2AZ, UK.

S. Sprenger

Nanoresins AG, Charlottenburger Strasse 9, 21502 Geesthacht, Germany.

\section{Abstract}

The present paper considers the mechanical and fracture properties of four different epoxy polymers containing 0,10 and $20 \mathrm{wt} \%$ of well-dispersed silica nanoparticles. Firstly, it was found that, for any given epoxy polymer, their Young's modulus steadily increased as the volume fraction, $v_{f}$, of the silica nanoparticles was increased. Modelling studies showed that the measured moduli of the different silica-nanoparticle filled epoxy-polymers lay between upper-bound values set by the Halpin-Tsai and the Nielsen 'no-slip' models, and lower-bound values set by the Nielsen 'slip' model; with the last model being the more accurate at relatively high values of $v_{f}$. Secondly, the presence of silica nanoparticles always led to an increase in the toughness of the epoxy polymer. However, to what extent a given epoxy polymer could be so toughened was related to structure/property relationships which were governed by (a) the values of glass transition temperature, $T_{g}$, and molecular weight, $M_{c}$, between cross-links of the epoxy polymer, and (b) the adhesion acting at the silicananoparticle/epoxy-polymer interface. Thirdly, the two toughening mechanisms which were operative in all the epoxy polymers containing silica nanoparticles were identified to be (a) localised shear-bands initiated by the stress concentrations around the periphery of the silica nanoparticles, and (b) debonding of the silica nanoparticles followed by subsequent plastic void-growth of the epoxy polymer. Finally, the toughening mechanisms have been quantitatively modelled and there was good agreement between the experimentally measured values and the predicted values of the fracture energy, $G_{c}$, for all the epoxy polymers modified by the presence of silica nanoparticles. The modelling studies have emphasised the important roles of the stress versus strain behaviour of the epoxy polymer and the silica-nanoparticle/epoxy-polymer interfacial adhesion in influencing the extent of the two toughening mechanisms, and hence the overall fracture energy, $G_{c}$, of the nanoparticle-filled polymers.

Keywords: Epoxy polymers; Compression tests; Fracture energy; Modelling studies; Nanoparticles; Strainsoftening; Toughening mechanisms.

*Corresponding authors:

A.J. Kinloch: Tel: +44 207594 7000, Fax: +44 207594 7238, email: a.kinloch@imperial.ac.uk

A.C. Taylor: Tel: +44 207594 7149, Fax: +44 207594 7017, email: a.c.taylor@imperial.ac.uk 


\section{Introduction}

Epoxy polymers are widely used for the matrices of fibre-reinforced composite materials and as adhesives. When cured, epoxy polymers are amorphous and highly-crosslinked (i.e. thermosetting) polymers. This microstructure results in many useful properties for structural engineering applications, such as a high modulus and failure strength, low creep, and good performance at elevated temperatures. However, the structure of such epoxy polymers also leads to a highly undesirable property in that they are relatively brittle materials, with a poor resistance to crack initiation and growth.

Nevertheless, it has been well established for many years that the incorporation of a second microphase of a dispersed rubber, e.g. [1-5], or a thermoplastic polymer, e.g. [6-9], into the epoxy polymer can increase their toughness. Here the rubber or thermoplastic particles are typically about 1 to $5 \mu \mathrm{m}$ in diameter with a volume fraction of about 5 to $20 \%$. However, the presence of the rubbery phase typically increases the viscosity of the epoxy monomer mixture and reduces the modulus of the cured epoxy polymer. Hence rigid, inorganic particles have also been used, as these can increase the toughness without affecting the glass transition temperature of the epoxy. Here glass beads or ceramic (e.g. silica or alumina) particles with a diameter of between 4 and $100 \mu \mathrm{m}$ are typically used, e.g. [10-15]. However, these relatively large particles also significantly increase the viscosity of the resin, reducing the ease of processing. In addition, due to the size of these particles they are unsuitable for use with infusion processes for the production of fibre composites, since they are strained-out by the relatively small gaps between the fibres.

More recently, a new technology has emerged which holds considerable promise for increasing the mechanical performance of such thermosetting polymers. This is via the addition of a nanophase structure in the polymer, where the nanophase consists of small rigid particles of silica [16-20]. Such nanoparticle modification has been shown to not only increase the toughness and cyclic-fatigue resistance of the epoxy polymer [20,21], but also due to the very small size of the silica particles not to lead to a significant increase in the viscosity of the epoxy monomer [22]. Indeed, previous work [20] has shown that the fracture energy, $G_{c}$, of the epoxy polymer that was studied could be increased from 77 to $212 \mathrm{~J} / \mathrm{m}^{2}$ by the addition of $20 \mathrm{wt} . \%$ of silica nanoparticles.

The aims of the present work are to investigate the toughness of epoxy polymers modified with silica nanoparticles for a wide range of different epoxy polymers. Four different epoxy systems were selected on the basis of trying to achieve a range of values for the glass transition temperatures, $T_{g}$, and molecular weights, $M_{c}$, between cross-links for the different unmodified epoxy-polymers. It was considered that this would enable a study of (a) whether the concept of toughening of epoxy polymers via the use of silica nanoparticles was applicable to a wide range of different epoxy polymers, and (b) whether the values of $T_{g}$ and $M_{c}$ of the unmodified epoxy polymer had a significant effect on the toughenability of the basic epoxy polymer via the use of silica nanoparticles. In the course of the present study, the structure/property relationships will be established and the toughening mechanisms which are operative will be identified and quantitatively modelled. 


\section{Experimental}

\subsection{Materials}

\subsubsection{Introduction}

In the present paper four different epoxy polymers were employed. They were modified with silica nanoparticles at 10 and $20 \mathrm{wt} . \%$, and due to the slightly different densities of the epoxy polymers this yields somewhat slightly different values for the volume fraction, $v_{f}$, of the added silica nanoparticles. The 'control', i.e. unmodified, epoxy-polymers were also studied. These polymers, and the cure conditions employed, are described below.

\subsubsection{The anhydride-cured DGEBA epoxy polymer}

This epoxy resin was a standard diglycidyl ether of bis-phenol A (DGEBA) with an epoxide equivalent weight (EEW) of 185 g/eq., 'LY556' supplied by Huntsman, UK. The silica $\left(\mathrm{SiO}_{2}\right)$ nanoparticles were supplied as a colloidal silica-sol at a concentration of $40 \mathrm{wt}$ \% in a DGEBA epoxy resin (EEW = $295 \mathrm{~g} / \mathrm{eq}$.) as 'Nanopox F400' from Nanoresins, Germany. The silica nanoparticles are synthesised from an aqueous sodium silicate solution $[21,23]$. They then undergo a process of surface modification, with an organosilane, and matrix exchange to produce a master-batch of $40 \mathrm{wt}$ \% (i.e. about 26 vol.\%) silica nanoparticles in the epoxy resin. The silica nanoparticles had a mean particle diameter of about $20 \mathrm{~nm}$, with a narrow range of particle-size distribution and laser light scattering revealed that almost all particles are between 5 to $35 \mathrm{~nm}$ in diameter. The particle size and excellent dispersion of these silica nanoparticles remain unchanged during any further mixing and/or blending operations. Further, despite the relatively high silica-nanoparticle content of about 26 vol\%, the nanofilled epoxy-resin still has a comparatively low viscosity due to the agglomerate-free colloidal dispersion of the nanoparticles in the resin. The curing agent was an accelerated methylhexahydrophthalic acid anhydride, 'Albidur HE 600' (anhydride equivalent weight (AEW) = 170 g/eq.), also supplied by Nanoresins. The DGEBA epoxy resin was mixed with the epoxy containing the silica nanoparticles to give the required concentration of silica nanoparticles. A stoichiometric amount of the curing agent was added to the mixture, which was stirred thoroughly and degassed at $50^{\circ} \mathrm{C}$ and $-1 \mathrm{~atm}$. The resin mixture was then poured into a pre-heated steel mould coated with release-agent, 'Frekote $700-\mathrm{NC}$ ' from Loctite, UK, and cured at $90^{\circ} \mathrm{C}$ for 1 hour and then post-cured at $160^{\circ} \mathrm{C}$ for 2 hours, using a ramp rate of $10^{\circ} \mathrm{C} /$ minute.

\subsubsection{The polyether-amine cured DGEBA/F epoxy polymer}

This epoxy was a blend of DGEBA and diglycidyl ether of bis-phenol F (DGEBF) resins with an EEW of 173 g/eq., namely 'Araldite AY 105-1' supplied by Huntsman, UK. The silica nanoparticles were again introduced by adding 'Nanopox F 400' (EEW = 295 g/eq.), Nanoresins, Germany. The resin mixtures were cured with a standard polyether-amine, with an amine-hydrogen equivalent weight (AHEW) of 60 g/eq., 'Jeffamine D230', Huntsman, UK. This resin and hardener were mixed to a ratio of 1:0.3 (epoxy:polyether-amine) to achieve a sub-stoichiometric composition as per [24]. These components were degassed, mixed for 15 minutes using a mechanical stirrer (at $200 \mathrm{rpm}$ and $50^{\circ} \mathrm{C}$ ) and degassed for a second time. The resin mixture was poured into the release-agent coated, pre-heated mould and cured for 3 hours at $75^{\circ} \mathrm{C}$ followed by a post cure of 12 hours at $110^{\circ} \mathrm{C}$, using a ramp rate of $10^{\circ} \mathrm{C} /$ minute. 


\subsubsection{The polyether-amine cured DGEBA epoxy polymer}

A polyether-amine cured epoxy was formulated using the DGEBA epoxy resin, 'LY556' and the addition of the silica nanoparticles was again achieved by adding 'Nanopox F400'. The epoxy resin was cured using 'Jeffamine D230' at stoichiometric quantities. The resin mixture was mixed and degassed as above, and then poured into the release-agent coated, pre-heated mould and cured for 3 hours at $75^{\circ} \mathrm{C}$ followed by a post cure of 12 hours at $110^{\circ} \mathrm{C}$, using a ramp rate of $10^{\circ} \mathrm{C} /$ minute.

\subsubsection{The amine-cured TGMDA epoxy polymer}

An amine-cured tetra-glycidylmethylenedianiline (TGMDA) epoxy polymer was also studied. The epoxy resin (EEW = 115 g/eq.) was obtained as 'Epikote 496' from Hexion, Germany. The silica nanoparticles were obtained pre-dispersed in a TGMDA epoxy resin and obtained from Nanoresins, Germany, as 'EPR 486' with an EEW = $180 \mathrm{~g} / \mathrm{eq}$. The amine curing agent was a blend of 'Lonzacure M-DEA' (EW = $158 \mathrm{~g} / \mathrm{eq}$.) and 'Lonzacure M-DIPA' (EW = $186 \mathrm{~g} / \mathrm{eq}$.), Lonza, Switzerland, obtained as powders and mixed to a 79:21 ratio and then added at a stoichiometric quantity to the resin. The hardener constituents were dissolved into the resin, which was first degassed to $-1 \mathrm{~atm}$. and at $90^{\circ} \mathrm{C}$, for one hour by mechanically stirring at $200 \mathrm{rpm}$ and $90^{\circ} \mathrm{C}$. The resin mixture was degassed a second time and then poured into the release-agent coated, preheated moulds and cured. The resins were cured at $160^{\circ} \mathrm{C}$ for 75 minutes and then post-cured at $180^{\circ} \mathrm{C}$ for 2 hours, using a $10^{\circ} \mathrm{C} /$ minute ramp rate.

\subsection{Microstructure and thermal studies}

Atomic force microscopy (AFM) studies were undertaken using a 'MultiMode' scanning probe microscope from Veeco, UK, equipped with a 'NanoScope IV' controlled 'J-scanner'. A smooth surface was first prepared by cutting samples of the cured plates of epoxy polymers, employing a 'PowerTome XL' cryo-ultramicrotome from RMC Products, UK, at temperatures down to $-100^{\circ} \mathrm{C}$. Then AFM scans were performed in the tapping mode using a silicon probe with a $5 \mathrm{~nm}$ tip, and both height and phase images were recorded.

Differential scanning calorimetry (DSC) was performed using a 'Q2000' from TA Instruments, UK, to ensure that the epoxies were fully cured, and secondly to obtain the glass transition temperature, $T_{g}$. Standard procedures exist for the determination of $T_{g}$, e.g. $[25,26]$, which were followed. The specific energy required to change the temperature of the $10 \mathrm{mg}$ sample per degree was monitored using a $10^{\circ} \mathrm{C} /$ minute rate for heating and cooling. Each sample was heated through a range from room temperature to about $60^{\circ} \mathrm{C}$ above the expected value of $T_{\mathrm{g}}$ twice, hence two values were obtained for each test. The value of $T_{\mathrm{g}}$ was taken as the mid-point of the inflexion curve and two repeat tests were conducted for each formulation.

The rubbery equilibrium tensile modulus, $E_{r}$, for the unmodified epoxies was obtained by conducting a dynamic mechanical thermal analysis (DMTA) test employing a 'Q800' machine from TA Instruments, UK, and using a three-point bend specimen. The samples were heated from room temperature to approximately $50^{\circ} \mathrm{C}$ above the $T_{g}$. A value for $E_{r}$ was determined as the plateau in the tensile storage modulus above the $T_{g}$. The molecular weight between cross-links, $M_{c}$, was calculated from [27-29]:

$$
\log _{10}\left(E_{r} / 3\right)=6.0+293 \rho / M_{c}
$$


where $M_{c}$ has the units of $\mathrm{g} / \mathrm{mol}, E_{r}$ has the units of $\mathrm{Pa}$, and $\rho$ is the density of the epoxy, in $\mathrm{g} / \mathrm{cm}^{3}$, and was determined using the immersion technique via ISO 1183 'Method A' [30]. The measured densities of the different epoxy polymers were in the range of $1.1-1.2 \mathrm{~g} / \mathrm{cm}^{3}$.

\subsection{Modulus and yield behaviour}

Uniaxial tensile tests were conducted on the epoxy polymers in accordance with ISO 527 [31, 32]. Tensile dumbbells were machined from the cured plates and were tested at a displacement rate of $1 \mathrm{~mm} / \mathrm{minute}$, and the displacement in the gauge length was measured using an extensometer. The tensile Young's modulus, $E$, and yield stress, $\sigma_{y}$, were ascertained.

The overall yield behaviour was ascertained using plane-strain compression tests, since the epoxy polymers failed around the yield point when the uniaxial tensile tests were undertaken. The plane-strain compression tests were conducted as described by Williams and Ford [33]. Tests were conducted using $3 \times 60 \times 40 \mathrm{~mm}^{3}$ specimens loaded in compression between two parallel, $12 \mathrm{~mm}$ wide, platens at a constant displacement rate of $0.1 \mathrm{~mm} /$ minute, and the results were corrected for the compliance of the test machine and test rig. The yield stress, $\sigma_{y c}$, was defined as the first locus of the true stress-true strain curve with a zero gradient. Optical cross-sections were cut from the compressed region, and then polished using a 'Labopol-21' from Struers, UK. They were then polished employing progressively finer grades of emery paper up to 4000 grit, which is equivalent to $3 \mu \mathrm{m}$ polishing powder. The samples were bonded onto standard glass slides using an optically-transparent, room-temperature curing, epoxy, 'Araldite 2020' from Huntsman, UK, and were finally polished to a nominal thickness of approximately $100 \mu \mathrm{m}$.

\subsection{Fracture tests}

Single-edge notch-bend (SENB) tests were conducted in accordance with ISO 13586 [34] to obtain values for the plane-strain initiation fracture energy, $G_{c}$, and fracture toughness, $K_{c}$, of the epoxy polymers. To obtain sharp cracks, the tips of the initial machine-notch in the SENB specimens were tapped using a cooled razor blade. Crack lengths of the order of $a / w=0.5$ were obtained, where $a$ is the crack length and $w$ is the width of the test specimen, and the thickness, $B$, of the SENB specimens was $6 \mathrm{~mm}$. The fracture energy was calculated using the energy method, and the fracture toughness was calculated using the fracture load [34]. As a cross-check, the fracture energy for each material was also calculated from the measured values of $K_{c}$ and the tensile modulus, $E$ [34]; and very good agreement between the values was found.

\subsection{Double-notched four-point bend tests}

Double-notched four-point bend (DN4PB) tests have been conducted to identify the mechanisms that contribute to the observed differences in toughness. This method has been previously employed very successfully by Sue et al. [35, 36] and Pearson et al. [37]. In this test, two near-identical natural cracks are produced by tapping a razor blade into each machined-notch. The specimen is then loaded in four-point bending, resulting in two near-identical stress fields at the crack tips. One of the cracks will propagate, and leave a second crack tip that is loaded to a near-critical fracture toughness for that material. The process-zone region directly ahead of this second crack tip can then be examined in detail, using such techniques as polarised transmission optical-microscopy or transmission electron microscopy. To ensure that there was a fully-developed process-zone ahead of the second crack tip, the calculated values of the fracture toughness 
from these tests were directly compared to those obtained from the SENB tests, and good agreement was found.

\subsection{Fractographic studies}

The fracture surfaces of the epoxy polymers were studied using high-resolution scanning electron-microscopy. This was performed using a scanning electron microscope (SEM) equipped with a field-emission gun (FEGSEM). A Carl Zeiss, Germany, 'Leo 1525' with a 'Gemini' column was used with a typical accelerating voltage of $5 \mathrm{kV}$. All specimens were coated with an approximately $5 \mathrm{~nm}$ thick layer of chromium before imaging. FEGSEM images have been used to study the debonding and any subsequent plastic void-growth of the polymer, and to estimate the percentage of silica nanoparticles that had debonded and resulted in void growth in the epoxy polymer during the fracture process. To check that a significant number of silica nanoparticles were included in the analysis, the area fraction of such particles was measured and compared to the known volume fraction of the particles. Within experimental error, no significant differences were recorded.

\section{Results and discussion}

\subsection{Microstructure}

In agreement with previous work [20], microscopy of all four of the unmodified epoxy-polymers showed that these were homogeneous thermoset polymers, see for example Fig. 1(a). The glass transition temperatures, $T_{g}$, from DSC measurements for the different unmodified epoxy-polymers are given in Table 1 and, as may be seen, a wide range of values were observed for the different epoxy polymers. Further, the tensile storage modulus, $E_{r}$, in the rubbery plateau region was measured and hence the molecular weight, $M_{c}$, between crosslinks for the epoxy polymers was determined, as described above. It is noteworthy that the two polyetheramine cured epoxy polymers have the lowest values of $T_{g}$ and possess the highest values of $M_{c}$, i.e. they have relatively very low $T_{g}$ values and a low cross-link density compared to the anhydride-cured DGEBA and the amine-cured TGMDA epoxy polymers.

Considering the epoxy polymers containing the silica nanoparticles, all the different epoxy polymers containing the nanoparticles exhibited a very well dispersed phase of silica nanoparticles, with no indications of any agglomeration of the nanoparticles, as illustrated in Figs. 1(b) and (c). Furthermore, the glass transition temperatures were unchanged upon addition of the silica nanoparticles, within experimental uncertainty, compared to the value of the unmodified epoxy polymer, as may be seen from Table 2. Similar results, showing no change in $T_{g}$ due to the addition of silica nanoparticles, have been reported by other authors [17, $20,38,39]$.

\subsection{Basic mechanical properties}

\subsubsection{Young's modulus}

The values of the Young's modulus, $E$, measured from the tensile tests are summarised in Table 2. Modulus values from 2.94 to $3.16 \mathrm{GPa}$ were measured for the unmodified (i.e. control) epoxy-polymers. The addition of silica nanoparticles increased the modulus as expected, since the modulus of silica, with $E=70 \mathrm{GPa}$ [40, 41], is much greater than that of the epoxy polymers. The moduli of the epoxy polymers containing nanoparticles, normalised to that of the unmodified epoxy, is shown as a function of the volume fraction, $v_{f}$, of silica 
nanoparticles in Fig. 2. The increase in the normalised modulus as a function of $v_{f}$ is approximately linear and all the different epoxy polymers follow the same relationship, within experimental error. The measured moduli may be compared to values from theoretical predictions, and there are many models that may be used to predict the moduli of such silica-particle modified polymers, see [42-44] for example. In the present work the Halpin-Tsai and the Nielsen models will be used, as these are considered to be the most applicable for the present systems [45].

The Halpin-Tsai model $[46,47]$ may be used to predict the modulus, $E$, of a material containing silica nanoparticles as a function of the modulus, $E_{u}$, of the polymer containing no silica nanoparticles, and of the modulus of the particles, $E_{p}$. The predicted modulus of the silica-particle modified epoxy-polymer, $E$, is given by:

$$
E=\frac{1+\zeta \eta V_{f}}{1-\eta V_{f}} E_{u}
$$

where $\zeta$ is the shape factor, $v_{f}$ is the volume fraction of particles, and $\eta$ is given by:

$$
\eta=\left(\frac{E_{p}}{E_{u}}-1\right) /\left(\frac{E_{p}}{E_{u}}+\zeta\right)
$$

By comparing their predictions with results from a finite-element analysis, Halpin and Kardos [47] have suggested that a shape factor of $\zeta=2 \mathrm{w} / \mathrm{t}$ should be used, where $\mathrm{w} / \mathrm{t}$ is the aspect ratio of the particles, when the particles are aligned with the loading direction. They recommended using $\zeta=2$ for the modulus perpendicular to the loading direction. For the spherical silica nanoparticles used in the present work, the aspect ratio is unity, and hence $\zeta=2$ will be used. The predictions are compared with the experimental data in Fig. 2 and, as may be seen, the Halpin-Tsai model, whilst giving an approximately linear relationship, does consistently over-predict the moduli of the nanoparticle-filled epoxy-polymers.

Considering the Nielsen model, then the basic Lewis-Nielsen model [48], using the work of McGee \& McCullough [49], gives the modulus, $E$, of the silica-nanoparticle modified epoxy polymer as:

$$
E=\frac{1+\left(k_{E}-1\right) \beta v_{f}}{1-\mu \beta v_{f}} E_{u}
$$

where $k_{E}$ is the generalised Einstein coefficient, and $\beta$ and $\mu$ are constants. The constant $\beta$ is given by:

$$
\beta=\left(\frac{E_{p}}{E_{u}}-1\right) /\left(\frac{E_{p}}{E_{u}}+\left(k_{E}-1\right)\right)
$$

It should be noted that $\beta$ is identical to $\eta$ in the Halpin-Tsai model when a shape factor of $\zeta=\left(k_{E}-1\right)$ is used. The value of $\mu$ depends on the maximum volume fraction of particles, $v_{\max }$, that can be incorporated and may be calculated from:

$$
\mu=1+\frac{\left(1-v_{f}\right)}{v_{\max }}\left[v_{\max } v_{f}+\left(1-v_{\max }\right)\left(1-v_{f}\right)\right]
$$

Values of $v_{\max }$ have been published by Nielsen and Landel [50] for a range of particle types and packing. The micrographs shown in the present work indicate that the silica nanoparticles in the epoxy polymer are nonagglomerated and randomly arranged. Nielsen and Landel quote a value of $v_{\max }=0.632$ for such random close-packed, non-agglomerated spheres, and this value will be used in the present modulus predictions. The 
value of $k_{E}$ varies with the degree of adhesion of the epoxy polymer to the particle. For an epoxy polymer with a Poisson's ratio of 0.5 which contains dispersed spherical particles then (a) $k_{E}=2.5$ if there is 'no slippage' at the interface (i.e. very good adhesion), or (b) $k_{E}=1.0$ if there is 'slippage' (i.e. relatively low adhesion) [50]. However, the value of $k_{E}$ is reduced when the Poisson's ratio, $v$, of the polymer is less than 0.5 [51]. In the present work $v=0.35$, so the values of $k_{E}$ will be reduced by a factor of 0.867 . Hence, in the present work, (a) $k_{E}=2.167$ if there is no slippage, or (b) $k_{E}=0.867$ if there is slippage at the interface [50]. The predictions for these two cases are given in Fig. 2, which shows that reducing the adhesion of the nanoparticle/epoxypolymer interface, i.e. to enable 'slippage', reduces the value of the predicted modulus. For the 'slip' version of the Nielsen model, the agreement between the predictions and the experimental data is excellent.

In summary, from Fig. 2, the best agreement is with the Nielsen 'slip' model. The Halpin-Tsai and the Nielsen 'no-slip' models both lead to somewhat higher predictions of the modulus, for a given value of $v_{f}$, and tend to over-predict the experimentally-measured moduli of the different epoxy polymers, compared to the Nielsen 'slip' model. It is of interest to note that these three models have been used previously to predict the moduli of both silica-nanoparticle and 'hybrid' (i.e. where both silica nanoparticles and rubber microparticles are present) filled epoxy-polymers $[20,45]$. These earlier studies also found that at relatively high values of $v_{f}$, above about 0.1 of silica nanoparticles, the Nielsen 'slip' model gave the best agreement with the measured values. However, unlike the present study, the earlier studies found that a relatively low values of $v_{f}$ (i.e. at values of $v_{f}$ below about 0.1 ) the Halpin-Tsai and the Nielsen 'no-slip' models gave better agreement. Thus, it would seem that an overall conclusion is that the measured moduli of the different silica-nanoparticle filled epoxy polymers approximately lay between an upper-bound value set by the Halpin-Tsai and the Nielsen 'noslip' models, and a lower-bound value set by the Nielsen 'slip' model, with the last model being the more accurate at relatively high values of $v_{f}$. Although, it should be noted that the mean value, and associated scatter band, for the normalised Young's modulus for the polyether-amine cured DGEBA/F does fall somewhat below the suggested lower-bound value, as defined by the Nielsen 'slip' model.

\subsubsection{Plane-strain compression behaviour}

The true stress versus true strain relationships for the unmodified epoxy-polymers from the plane-strain compression tests are shown in Fig. 3. As may be seen, the relationships all exhibit broadly similar features. Namely a clearly defined yield stress, $\sigma_{y c}$, followed by some strain-softening, where the stress now decreases as the strain further increases. This strain-softening region is then followed by a well-defined strain-hardening region up to a final fracture strain, $\gamma_{f}$. The values of the true tensile yield stress, $\sigma_{y}$, true compressive yield stress, $\sigma_{y c}$, and true fracture strain, $\gamma_{f}$, for the unmodified epoxy-polymers are given in Table 3 , where the typical coefficient of variation from replicate tests was $\pm 3 \%$. In Table 3 , the relatively low values of the compressive yield stress, $\sigma_{y c}$, (and also of the tensile yield stress, $\sigma_{y}$ ) and high values of the fracture strain, $\gamma_{f}$, for the polyether-amine cured DGEBA/F and polyether-amine cured DGEBA epoxy polymers, which possess similar and relatively low $T_{g}$, and high $M_{c}$, values, see Table 1 , are especially noteworthy.

As described above, transmission optical micrographs, using cross-polarised light, of polished sections were taken of the unmodified epoxy-polymers which had been loaded to within the strain-softening region during the plane-strain compression tests. The transmission optical micrographs are shown in Fig. 4. They clearly show that, for all the unmodified epoxy-polymers, birefringent shear bands form in the test specimen 
after the yield stress has been attained and the strain-softening region has been entered. This observation is in accord with the work of Bowden et al. $[52,53]$ who demonstrated that the occurrence of inhomogeneous plastic deformation, e.g. the formation of plastic shear bands, resulted from the presence of a strain-softening region in the true-stress versus true-strain relationship for a polymer. It has also been established that such deformation is stabilised by strain-hardening then taking place [54]. The implication of the above results will be discussed further later, when the toughening mechanisms initiated by the presence of the silica nanoparticles are described and modelled.

\subsection{Fracture properties}

The values of the fracture toughness, $K_{c}$, and the fracture energy, $G_{c}$, for the unmodified and silicananoparticle filled epoxy-polymers are shown in Table 2. As may be seen, as the volume fraction, $v_{f}$, of the silica nanoparticle phase is increased, the values of $K_{c}$ and $G_{c}$ both steadily increase. From the results shown in Tables 1 and 2, the anhydride-cured DGEBA and amine-cured TGMDA materials possess significantly higher glass transition temperatures (i.e. $T_{g}$ values of 143 and $186^{\circ} \mathrm{C}$, respectively) and the lowest molecular weights, $M_{c}$, between cross-links (i.e. $M_{c}$ values of 408 and $393 \mathrm{~g} / \mathrm{mol}$, respectively) of the epoxy polymers; and they exhibit the lowest values of toughness, see Table 2. This observation is in agreement with similar trends from previous workers $[29,55]$.

In Fig. 5 values of the fracture energy, normalised to that of the unmodified epoxy polymer, are plotted versus the volume fraction, $v_{f}$, of silica nanoparticles for the different epoxy polymers. The results clearly confirm the relative difficulty of toughening the anhydride-cured DGEBA and amine-cured TGMDA epoxy polymers which possess the relatively high $T_{g}$ and low $M_{c}$ values. Indeed, the four different types of epoxy polymer fall into two distinct sets which may be both represented by a linear relationship between the normalised fracture energy and $v_{f}$, but the linear relationships have a different slope for the two sets of results. These linear relationships shown in Fig. 5 reveal that the polyether-amine cured DGEBA/F and polyetheramine cured DGEBA epoxy polymers, which possess similar and relatively low $T_{g}$, and high $M_{c}$, values (see Table 1), are both capable of being toughened to a significantly greater extent compared to the anhydridecured DGEBA and amine-cured TGMDA epoxy polymers.

\section{Modelling studies}

\subsection{Introduction}

A previous study [45] has considered the toughening mechanisms induced by the silica nanoparticles in detail. The toughening mechanisms of (a) crack pinning, (b) crack deflection, and (c) immobilised polymer around the particles were all discounted. Instead, the ability of the silica nanoparticles to induce an increased extent of plastic deformation of the epoxy polymer was identified as the dominant toughening mechanism. The results of the present study are in complete agreement with this earlier work, and two types of plastic deformation mechanisms in the epoxy polymer have been identified, which dissipate energy in a region around the crack tip and so effectively blunt the crack tip. These are (a) localised shear-bands initiated by the stress concentrations around the periphery of the silica nanoparticles, and (b) debonding of the silica nanoparticles followed by subsequent plastic void-growth of the epoxy polymer. These two deformation mechanisms, both of which involve the epoxy polymer undergoing localised, inhomogeneous, plastic deformation as a result of the 
silica nanoparticles being present in a 'process' or 'plastic' zone ahead of the crack tip, are discussed qualitatively below. Also, a quantitative model is employed to predict the extent of toughening induced by the presence of the silica nanoparticles in the different epoxy polymers. Further, the toughening mechanisms, and the extent to which they contribute to the overall toughness, $G_{c}$, of the nano-particle-modified epoxy-polymers are also discussed with respect to the structure/property relationships which have been identified above.

\subsection{The shear-banding mechanism}

The true stress versus true strain relationships for the unmodified epoxy-polymers from the plane-strain compression tests shown in Fig. 3 reveal that all of these polymers exhibited strain-softening which is known to lead to the formation of inhomogeneous, localised plastic-deformation [e.g. 52-53]; and indeed the tendency of the epoxy polymers to form localised, plastic shear-bands was confirmed from the transmission optical micrographs shown in Fig. 4.

From the double-notched four-point bend (DN4PB) tests, the localised shear-yielding around the crack tip in the silica-nanoparticle filled epoxy-polymers may be observed. A typical transmission optical micrograph, taken between crossed polarisers, of the anhydride-cured DGEBA epoxy polymer containing a volume fraction of 0.065 of silica nanoparticles is shown in Fig. 6. For clarity this is taken at the edge of the sample under plane-stress conditions, as the plastic zone in the central part of the specimen (which is under plane-strain conditions) was too small to image satisfactorily. The birefringence of the plastically-deformed regions in the micrograph in Fig. 6 reveals the localised plastic-deformation that has occurred in the epoxy polymer immediately ahead of the crack tip. The region closest to the fracture plane is relatively intense in nature, whilst the outermost regions clearly suggest that the deformation does occur in localised micro shear-bands which appear to merge to form the localised, but diffuse, plastic-zone region. The size of the plastic-zone region may be measured from these micrographs and compared to theoretical predictions. The Irwin model states that the radius of the plastic zone, $r_{y}$ (plane stress), can be calculated using [56]:

$$
r_{y}(\text { plane stress })=\frac{1}{2 \pi} \frac{E G_{C}}{\sigma_{y}^{2}}
$$

where $E$ is the Young's modulus, $G_{c}$ is the fracture energy, and $\sigma_{y}$ is the tensile yield stress of the polymer. Substitution of the relevant parameters into Eq. (7) gives a predicted value of $r_{y}$ (plane stress) of about $10 \mu \mathrm{m}$ and the value measured from the micrographs was $12 \pm 3 \mu \mathrm{m}$. Thus, there is very good agreement between the predicted and the experimental values. Similar good agreement has been observed by Liang and Pearson in their recent work [38].

\subsection{The plastic void-growth mechanism}

The toughening mechanisms associated with rigid, e.g. silica, micrometre-sized particles have frequently been shown to be due to debonding of the particle followed by plastic void-growth and shear yielding, e.g. [15, 57]. Indeed, Kinloch and Taylor [58] have also demonstrated that the voids around such inorganic particles closedup when the epoxy polymer was heated above its glass-transition temperature, $T_{g}$, and allowed to relax. For nanoparticles, the debonding process is generally considered to absorb little energy compared to the plastic deformation of the epoxy polymer [59-61]. However, debonding is essential because this reduces the 
constraint at the crack tip, and hence allows the epoxy polymer to deform plastically via a void-growth mechanism.

Now, high-resolution scanning electron microscopy (FEG-SEM) of a fracture surface of the polyetheramine cured DGEBA/F epoxy polymer is shown in Fig. 7(a), and is essentially featureless. On the other hand, a FEG-SEM micrograph of a fracture surface of the polyether-amine cured DGEBA/F epoxy polymer containing a volume fraction, $v_{f}$, of 0.133 of silica nanoparticles showed the presence of voids around many of the silica nanoparticles, see Figs. $7($ b) and $7(\mathrm{c})$. This demonstrates that plastic void-growth of the epoxy polymer, initiated by debonding of the silica nanoparticles, has occurred for this material. The diameter of these voids is typically about $30 \mathrm{~nm}$. Such voids were observed on the fracture surfaces of all the polyetheramine cured DGEBA/F and the anhydride-cured DGEBA epoxy polymers containing silica nanoparticles. It should be noted that, although the samples are coated to prevent charging in the electron microscope, the voids are not an artefact of the coating as they could not be observed on a coated fracture surface of the unmodified epoxy polymer [45]. Also the silica nanoparticle-modified epoxy samples appeared similar whether they were coated with chromium or gold. In addition, similar voids have been observed using AFM [45]. However, as may be clearly seen from Figs. 7(b) and (c), not all of the silica nanoparticles have debonded. This may arise (a) from the purely statistical aspect of the fracture process, or (b) from the fact that once a silica nanoparticle, or group of such particles, have debonded and the epoxy polymer started to undergo plastic void-growth then the triaxial stress which drives such a mechanism is relieved in the adjacent region. The percentage of the silica nanoparticles which undergo such debonding, and subsequent void growth around them, has been counted, independently, by several of the present authors from micrographs such as that shown in Figs. 7(b) and (c). For both volume fractions of silica nanoparticles in the anhydride-cured DGEBA and the polyether-amine cured DGEBA/F epoxy polymers, the estimated percentage of such silica nanoparticles is $15 \pm 5 \%$. Within the experimental scatter, this value is independent of (a) whether the anhydride-cured DGEBA or the polyether-amine cured DGEBA/F epoxy was the epoxy polymer, and (b) the volume fraction of silica nanoparticles. Turning to the silica-nanoparticle modified polyether-amine cured DGEBA and amine-cured TGMDA epoxy polymers, no such voids around silica nanoparticles in these polymers were detectable.

\subsection{The model}

The model employed in the present work has been developed and described in detail in previous papers by Huang and Kinloch [62] and Hsieh et al. [20]. Therefore, only a brief summary will be given here. For the mechanisms of interest, Huang and Kinloch [62] proposed that the fracture energy, $G_{c}$, may be expressed by:

$$
G_{c}=G_{c u}+\Psi
$$

where $G_{c u}$ represents the fracture energy of the unmodified epoxy-polymer and $\Psi$ represents the overall toughening contributions activated by the presence of the particulate phase. Obviously, $\Psi$ contains the contributions from the different toughening mechanisms and, in the present work, can be separated into the two terms:

$$
\Psi=\Delta G_{s}+\Delta G_{v}
$$


where $\Delta G_{s}$ and $\Delta G_{v}$ represent the contributions to the overall increase in the fracture energy, $G_{c}$, from the localised plastic shear-banding and plastic void-growth mechanisms, respectively.

Now, Hsieh et al. [20] expanded the term $\Delta G_{s}$ from the Huang and Kinloch model [62] so that it could be determined from:

$$
\Delta G_{s}=0.5 v_{f} \sigma_{y c} \gamma_{f} F^{\prime}\left(r_{y}\right)
$$

where $v_{f}$ is the volume fraction of particles, $\sigma_{y c}$ and $\gamma_{f}$ are the plane-strain compressive yield stress and fracture strain for the unmodified epoxy polymer, respectively, see Table 3. The parameter $F^{\prime}\left(r_{y}\right)$ is a geometric term based upon the assumption of a cubic array of particles. It is given by [20,63]:

$$
\begin{aligned}
F^{\prime}\left(r_{y}\right)=r_{y}\left[(4 \pi / 3 v)^{1 / 3}\left(1-r_{p} / r_{y}\right)^{3}\right. & \\
& \left.-(8 / 5)\left(1-r_{p} / r_{y}\right)\left(r_{p} / r_{y}\right)^{5 / 2}-(16 / 35)\left(r_{p} / r_{y}\right)^{7 / 2}-2\left(1-r_{p} / r_{y}\right)^{2}+(16 / 35)\right]
\end{aligned}
$$

where the $r_{p}$ is the radius of the particle and $r_{y}$ is the radius of the plane-strain plastic zone at the crack tip at fracture in the nanoparticle-modified polymer. The value of $r_{y}$ is given by:

$$
r_{y}=K_{v m p}^{2}\left(1+\mu_{m} / 3^{1 / 2}\right)^{2} r_{y u}
$$

where the term $\mu_{m}$ is a material constant which allows for the pressure-dependency of the yield stress and has a value of 0.2 [64]. The term $K_{v m p}$ is the maximum stress concentration for the von Mises stresses around a rigid particle. The value of $K_{v m p}$ is dependent on the volume fraction of particles, and was calculated by fitting to the data of Guild and Young $[65,66]$ obtained via finite-element analysis. The value of $K_{v m p}$ varies from approximately 1.60 to 1.73 over the range of volume fractions used in the present work. The term $r_{y u}$ is the plane-strain plastic-zone size at the crack tip fracture for the unmodified epoxy-polymer, and may it be readily calculated from [67]:

$$
r_{y u}=\frac{1}{6 \pi} \frac{E G_{C}}{\left(1-v^{2}\right) \sigma_{y}^{2}}
$$

where $E, v$ and $\sigma_{y}$ are the modulus, Poisson's ratio (taken to be 0.35 ) and tensile yield stress of the unmodified epoxy polymer, respectively. If the tensile specimen fractures before yielding, see Table 3 , then the tensile yield stress, $\sigma_{y}$, may be ascertained from the measured compressive yield stress, $\sigma_{y c}$, from [62]:

$$
\sigma_{y}=\sigma_{y c} \frac{\left(\sqrt{3}-\mu_{m}\right)}{\left(\sqrt{3}+\mu_{m}\right)}
$$

The studies of Huang and Kinloch [62] give the contribution $\Delta G_{v}$ to the toughness from the plastic voidgrowth mechanism as:

$$
\Delta G_{v}=\left(1-\mu_{m}^{2} / 3\right)\left(v_{f v}-v_{f p}\right) \sigma_{y c} r_{y u} K_{v m v}^{2}
$$

where $v_{f v}$ and $v_{f p}$ are the volume fraction of the voids and the volume fraction of particles which debond, respectively. The terms $v_{f v}$ and $v_{f p}$ may be directly measured from the appropriate electron micrographs, as described and given above, and the value of $r_{y u}$ may be calculated from Eq. (13). In Eg. (15), $K_{v m v}$ is the maximum stress concentration for the von Mises stresses around a debonded particle, i.e. a void. The value of 
$K_{v m v}$ has been calculated via finite-element analysis by Huang and Kinloch [62, 68] and varies with volume fraction in the range 2.11 to 2.12 for the volume fractions considered in the present work. (It should be recalled that, from the FEG-SEM studies discussed above, no voids around the silica nanoparticles in the modified polyether-amine cured DGEBA and amine-cured TGMDA epoxy polymers were ever detected. Hence, for these materials the terms $v_{f v}$, and $v_{f p}$, are both zero, and thus $\Delta G_{v}=0$.)

The value of $\Psi$ may now be evaluated from Eq. (9), via Eqs. (10) and (15) to give:

$$
\Psi=0.5 V_{f} \sigma_{y c} \gamma_{f} F^{\prime}\left(r_{y}\right)+\left(1-\mu_{m}^{2} / 3\right)\left(v_{f v}-v_{f p}\right) \sigma_{y c} r_{y u} K_{v m v}^{2}
$$

where the term $F^{\prime}\left(r_{y}\right)$ is defined in Eqs. (11) and (12), and the term $r_{y u}$ is defined in Eq. (13). The model to predict the fracture energy, $G_{c}$, may now be applied to the different epoxy polymers containing the silica nanoparticles.

\subsection{Comparison of measured and predicted values of $G_{c}$}

From the above equations and the values given for the various parameters in the tables and the text, the contributions $\Delta G_{s}$ and $\Delta G_{v}$ to the localised plastic shear-banding and plastic void-growth mechanisms in the silica-nanoparticle modified epoxy-polymers may be directly calculated. Hence, the value of the fracture energy, $G_{c}$, of the epoxy polymers may be ascertained from Eqs. (8) and (16). The predicted values are compared to the experimentally measured values in Table 4.

Firstly, there is good agreement between the measured values and those predicted from the above model. Indeed, this good agreement is especially noteworthy when the lack of any adjustable fitting terms in the above equations is considered.

Secondly, the model, see Eq. (8) and (16), also reveals that the relatively high fracture strains, see Fig. 3 and Tables 3 and 4 , of the two polyether-amine cured epoxy polymers, which possess similar and relatively low $T_{g}$, and high $M_{c}$, values, are a major reason for the higher values of $G_{c}$ which were observed.

Thirdly, the reason that the polyether-amine cured DGEBA/F epoxy polymer modified with the silica nanoparticles is somewhat tougher than the corresponding polyether-amine cured DGEBA epoxy polymer arises from the fact that for the latter material the term $\Delta G_{v}=0$ in Eq. 9, i.e. no debonding of the silica nanoparticles and subsequent void growth in the epoxy polymer was observed in the polyether-amine cured DGEBA epoxy polymer. This lack of observed debonding implies that the adhesion at the silicananoparticles/epoxy-polymer interfaces is relatively high in the polyether-amine cured DGEBA material. Hence, nanoparticle debonding, the precursor to void growth, does not occur in this modified polyether-amine cured DGEBA epoxy polymer. To support this suggestion the work of Vörös and Pukánszky [69, 70] is very relevant, since their studies concluded that relatively good particle/polymer interfacial adhesion was required in rigid-particulate filled polymers in order to observe an increase in the yield stress as a function of the volume fraction, $v_{f}$, of the particulate phase. They developed a theoretical model to explain the variation of the relationship between the normalised yield stress versus volume fraction, $v_{f}$, which embodied a parameter, $k$. The parameter $k$ is the proportionality constant for stress transfer across the particle/polymer interface: the higher the value of $k$, then higher is the level of interfacial adhesion. A plot of the normalised true compressive yield stress against the volume fraction, $v_{f}$, of silica nanoparticles in the different epoxy polymers is shown in Fig. 8. The lines represent the predictions of the model of Vörös and Pukánszky $[69,70]$ using the values of 
the parameter, $k$, as stated. Now, as may be seen in Fig. 8, only in both the nanoparticle-modified epoxypolymers where $\Delta G_{v}=0$, i.e. the modified amine-cured TGMDA and polyether-amine cured DGEBA epoxy polymers, did the values of the normalised true compressive yield stress increase significantly with the volume fraction, $v_{f}$, of the silica nanoparticles. Further, as expected from this theoretical work $[69,70]$, for these two polymers the values of the proportionality constant, $k$, for interfacial stress transfer are relatively high. Therefore, based on the approach of Vörös and Pukánszky [69, 70], there is definite evidence that the adhesion at the silica-nanoparticles/epoxy-polymer interfaces is relatively high for the modified amine-cured TGMDA and polyether-amine cured DGEBA epoxy polymers; and is significantly greater than that for the modified anhydride-cured DGEBA and polyether-amine cured DGEBA/F epoxy polymers. Indeed, in the present work, it was found that only in these last two nanoparticle-modified materials did particle debonding and subsequent plastic void-growth occur, and hence $\Delta G_{v}>0$.

Finally, to summarise, the polyether-amine cured DGEBA/F epoxy polymer containing the silica nanoparticles may be very readily toughened to a relatively very high extent since it: (a) exhibits strainsoftening followed by strain-hardening which allows the ready formation, and then stabilisation, of plastic deformation associated with the silica nanoparticles; (b) possesses a relatively low $T_{g}$, and high $M_{c}$, which lead to a relatively high plastic failure strain being achieved; and (c) possesses relatively low adhesion at the nanoparticle/polymer interface which allows the silica nanoparticles to debond in the triaxial stress-field ahead of the crack tip and so enables plastic void-growth in the epoxy polymer to develop.

\section{Conclusions}

The mechanical and fracture properties of four different epoxy polymers containing 0,10 and $20 \mathrm{wt} \%$ of welldispersed silica nanoparticles have been studied. Several major conclusions may be reached from the present work.

Firstly, considering the Young's modulus of these materials, then as the volume fraction, $v_{f}$, of the silica nanoparticles was increased the modulus of the epoxy polymer steadily increased, as would be expected. It was concluded that the experimentally-measured moduli of the different silica-nanoparticle filled epoxypolymers from the present study, and previous work [20, 45], lay approximately between upper-bound values set by the Halpin-Tsai and the Nielsen 'no-slip' models and the lower-bound values set by the Nielsen 'slip' model, with the last model being the more accurate at relatively high values of $v_{f}$.

Secondly, the presence of silica nanoparticles always led to an increase in the toughness of the epoxy polymers. Thus, all the different types of epoxy polymer could be significantly toughened using this approach. However, to what extent a given epoxy polymer could be so toughened was related to structure/property relationships which appear, in turn, to be governed by (a) the values of glass transition temperature, $T_{g}$ and molecular weight, $M_{c}$, between cross-links of the epoxy polymer, and (b) the level of adhesion acting at the silica-nanoparticle/epoxy-polymer interface.

Thirdly, the two toughening mechanisms which were operative in all the epoxy polymers containing silica nanoparticles have been identified. Namely, (a) localised plastic shear-bands initiated by the stress concentrations around the periphery of the silica nanoparticles, and (b) debonding of the silica nanoparticles followed by subsequent plastic void-growth of the epoxy polymer. These two deformation mechanisms both 
involve the epoxy polymer undergoing inhomogeneous, plastic deformation and it has been suggested that this arises from the ability of all these epoxy polymers to undergo strain-softening, which leads to the localised nature of the plastic deformation, followed by extensive strain-hardening, which stabilises such localised plastic deformation.

Fourthly, the two toughening mechanisms have been quantitatively modelled and there was good agreement between the experimentally-measured values and the predicted values of the fracture energy, $G_{c}$, for all the epoxy polymers modified with silica nanoparticles. The modelling studies emphasised the important roles of (a) the stress versus strain behaviour of the epoxy polymer, and (b) the silica-nanoparticle/epoxypolymer interfacial adhesion, and hence the ability for particle debonding to occur, in influencing the extent of the two toughening mechanisms, and hence the overall fracture energy, $G_{c}$, of the nanoparticle-filled polymers.

Finally, considering for example the toughest material that was identified, it has been postulated that the polyether-amine cured DGEBA/F epoxy polymer containing the silica nanoparticles may be very readily toughened by silica nanoparticles to a relatively very high extent since: (a) even at a relatively high concentration, the silica nanoparticles are present as a very well-dispersed phase in the epoxy polymer, with no indications of any agglomeration of the nanoparticles; (b) the epoxy polymer exhibits strain-softening followed by strain-hardening which allows the ready formation, and then stabilisation, of plastic deformation associated with the silica nanoparticles; (c) the epoxy polymer possesses a relatively low glass transition temperature, $T_{g}$, and high molecular weight, $M_{c}$, between cross-links which lead to a relatively high plastic failure strain to be achieved; and (c) there is relatively low adhesion at the nanoparticle/polymer interface which allows the silica nanoparticles to debond in the triaxial stress-field ahead of the crack tip and so enables plastic void-growth in the epoxy polymer to develop. 


\section{Acknowledgments}

The authors dedicate the present paper to Professor Sir Hugh Ford, FREng FRS (1913-2010), who was at Imperial College London for over 75 years and had the tremendous foresight in the early 1960s to initiate research on the deformation and fracture of polymers in the Department of Mechanical Engineering. We thank his former PhD student, Professor J.G. Williams, FREng FRS, for helpful discussions during the course of this work. We would also wish to thank Professor R.J. Young, FREng, University of Manchester, and Professor C.B. Bucknall, Cranfield University, for helpful discussions and comments. 


\section{References}

1. Rowe, E.H., A.R. Siebert and R.S. Drake, Toughening thermosets with butadiene/acrylonitrile polymers, Mod Plast, 47, 110-117 (1970).

2. Drake, R.S. and A.R. Siebert, Elastomer-modified epoxy adhesives for structural applications, SAMPE Quart, 6(4), 11-21 (1975).

3. Kinloch, A.J., S.J. Shaw, D.A. Tod and D.L. Hunston, Deformation and fracture behaviour of a rubbertoughened epoxy: 1. Microstructure and fracture studies, Polymer, 24(10), 1341-1354 (1983).

4. Pearson, R.A. and A.F. Yee, Toughening mechanisms in elastomer-modified epoxies. 2. Microscopy studies, J Mater Sci, 21(7), 2475-2488 (1986).

5. Kinloch, A.J., Theme article - toughening epoxy adhesives to meet today's challenges, Mater Res Soc Bull, 28(6), 445-448 (2003).

6. Bucknall, C.B. and I.K. Partridge, Phase separation in epoxy resins containing polyethersulphone, Polymer, 24(5), 639-644 (1983).

7. Kinloch, A.J., M.L. Yuen and S.D. Jenkins, Thermoplastic-toughened epoxy polymers, J Mater Sci, 29(14), 3781-3790 (1994).

8. Pascault, J.P. and R.J.J. Williams, Formulation and characterization of thermoset-thermoplastic blends, in Polymer Blends Volume 1: Formulation, Ed. D.R. Paul and C.B. Bucknall, p.379-416 (John Wiley \& Sons, New York, USA, 1999).

9. Brooker, R.D., A.J. Kinloch and A.C. Taylor, The morphology and fracture properties of thermoplastictoughened epoxy polymers, J Adhesion, 86(9), 726-741 (2010).

10. Young, R.J. and P.W.R. Beaumont, Failure of brittle polymers by slow crack growth. Part 2: Failure processes in a silica particle-filled epoxy resin composite, J Mater Sci, 10(8), 1343-1350 (1975).

11. Spanoudakis, J. and R.J. Young, Crack propagation in a glass particle-filled epoxy resin: Part 1. Effect of particle volume fraction and size, J Mater Sci, 19(2), 473-486 (1984).

12. Kinloch, A.J., D.L. Maxwell and R.J. Young, The fracture of hybrid-particulate composites, J Mater Sci, 20(11), 4169-4184 (1985).

13. Amdouni, N., H. Sautereau and J.F. Gerard, Epoxy composites based on glass beads. II. Mechanical properties, J Appl Polym Sci, 46(10), 1723-1735 (1992).

14. Lee, J., Fracture of glass bead/epoxy composites: on micro-mechanical deformations, Polymer, 41(23), 8363-8373 (2000).

15. Kawaguchi, T. and R.A. Pearson, The effect of particle-matrix adhesion on the mechanical behavior of glass filled epoxies. Part 2. A study on fracture toughness, Polymer, 44(15), 4239-4247 (2003).

16. Kinloch, A.J., J.H. Lee, A.C. Taylor, S. Sprenger, C. Eger and D. Egan, Toughening structural adhesives via nano- and micro-phase inclusions, J Adhesion, 79(8-9), 867-873 (2003).

17. Kinloch, A.J., R. Mohammed, A.C. Taylor, C. Eger, S. Sprenger and D. Egan, The effect of silica nano particles and rubber particles on the toughness of multiphase thermosetting epoxy polymers, J Mater Sci, 40(18), 5083-5086 (2005).

18. Ragosta, G., M. Abbate, P. Musto, G. Scarinzi and L. Mascia, Epoxy-silica particulate nanocomposites: Chemical interactions, reinforcement and fracture toughness, Polymer, 46(23), 10506-10516 (2005).

19. Zhang, H., Z. Zhang, K. Friedrich and C. Eger, Property improvements of in situ epoxy nanocomposites with reduced interparticle distance at high nanosilica content, Acta Mater, 54(7), 1833-1842 (2006).

20. Hsieh, T.H., A.J. Kinloch, K. Masania, J. Sohn Lee, A.C. Taylor and S. Sprenger, The toughness of epoxy polymers and fibre composites modified with rubber microparticles and silica nanoparticles, J Mater Sci, 45(5), 1193-1210 (2010).

21. HanseChemie, Patent Application, Patent Application, wo 02/083776 A1, (2002).

22. Roscher, C., Tiny particles, huge effect: Radiation curable silica nanocomposites for scratch and abrasion resistant coatings, European Coatings J, 4(3), 131-141 (2003).

23. Sprenger, S., C. Eger, A.J. Kinloch, A.C. Taylor, J.H. Lee and D. Egan, Nanoadhesives: toughness and high strength, Adhaesion, Kleben \& Dichten, 2003(3), 24-28 (2003). 
24. Burton, B., D. Alexander, H. Klein, A. Garibay-Vasquez, A. Pekarik and C. Henkee, Epoxy formulations using Jeffamine polyether-amines, Huntsman: TX. (2005).

25. ISO-11357, Plastics - Differential scanning calorimetry (DSC). Determination of glass transition temperature, British Standards Institute, London. (1999).

26. ASTM-D7426, Standard test method for assignment of the DSC procedure for determining $T_{g}$ of a polymer or an elastomeric compound, American Society for Testing and Materials: West Conshohocken. (2008).

27. Nielsen, L.E., Cross-linking effect on physical properties of polymers, J Macro Sci, 3(Part C), 69-103 (1969).

28. Timm, D.C., A.J. Ayorinde and R.F. Foral, Epoxy mechanical properties: Function of crosslink architecture, Brit Polym J, 17(2), 227-232 (1985).

29. Kinloch, A.J., C.A. Finch and S. Hashemi, Effect of segmental molecular mass between cross-links of the matrix phase on the toughness of rubber-modified epoxies, Polym Comm, 28(12), 322-325 (1987).

30. ISO-1183, Plastics - Methods for determining the density of non-cellular plastics, in Part 1: Immersion method, liquid pyknometer method and titration method, International Standards Organisation: Geneva. (2004).

31. ISO-527-1, Plastics - Determination of tensile properties - Part 1: General principles, International Standards Organisation: Geneva. (1993).

32. ISO-527-2, Plastics - Determination of tensile properties - Part 2: Test conditions for moulding and extrusion plastics, International Standards Organisation: Geneva. (1996).

33. Williams, J.G. and H. Ford, Stress-strain relationships for some unreinforced plastics, J Mech Eng Sci, 6(4), 405-417 (1964).

34. ISO-13586, Plastics - Determination of fracture toughness $\left(G_{I C}\right.$ and $\left.K_{I C}\right)$ - Linear elastic fracture mechanics (LEFM) approach, International Standards Organisation: Geneva. (2000).

35. Sue, H.-J., Study of rubber-modified brittle epoxy systems. Part II: Toughening mechanisms under mode-I fracture, Polym Eng \& Sci, 31(4), 275-288 (1991).

36. Sue, H.J. and A.F. Yee, Study of fracture mechanisms of multiphase polymers using the double-notch four-point-bending method, J Mater Sci, 28(11), 2975-2980 (1993).

37. Pearson, R.A. and A.F. Yee, Influence of particle size and particle size distribution on toughening mechanisms in rubber-modified epoxies, J Mater Sci, 26(14), 3828-3844 (1991).

38. Liang, Y.L. and R.A. Pearson, Toughening mechanisms in epoxy-silica nanocomposites (ESNs), Polymer, 50(20), 4895-4905 (2009).

39. Baller, J., N. Becker, M. Ziehmer, M. Thomassey, B. Zielinski, U. Müller and R. Sanctuary, Interactions between silica nanoparticles and an epoxy resin before and during network formation, Polymer, 50(14), 3211-3219 (2009).

40. Goodfellow Product Catalogue, Goodfellow, (Huntingdon, 2005).

41. Pascoe, K.J., An introduction to the properties of engineering materials, 3rd ed., (Van Nostrand Reinhold, London, 1978).

42. Kerner, E.H., The elastic and thermo-elastic properties of composite media, Proc Phys Soc, 69(8), 808813 (1956).

43. Nielsen, L.E., Simple theory of stress-strain properties of filled polymers, J Appl Polym Sci, 10, 97-103 (1966).

44. Halpin, J.C. and N.J. Pagano, The laminate approximation for randomly oriented fibrous composites, J Comp Mater, 3(4), 720-724 (1969).

45. Johnsen, B.B., A.J. Kinloch, R.D. Mohammed, A.C. Taylor and S. Sprenger, Toughening mechanisms of nanoparticle-modified epoxy polymers, Polymer, 48(2), 530-541 (2007).

46. Halpin, J.C., Stiffness and expansion estimates for oriented short fiber composites, J Comp Mater, 3 , 732-734 (1969).

47. Halpin, J.C. and J.L. Kardos, The Halpin-Tsai equations: a review, Polym Eng \& Sci, 186(5), 344-352 (1976). 
48. Lewis, T.B. and L.E. Nielsen, Dynamic mechanical properties of particulate-filled composites, J Appl Poly Sci, 14(6), 1449-1471 (1970).

49. McGee, S. and R.L. McCullough, Combining rules for predicting the thermoelastic properties of particulate filled polymers, polymers, polyblends, and foams, Polym Compos, 2(4), 149-161 (1981).

50. Nielsen, L.E. and R.F. Landel, Mechanical properties of polymers and composites. $2^{\text {nd }}$ Ed., (Marcel Dekker, New York, 1994).

51. Nielsen, L.E., The relation between viscosity and moduli of filled systems, J Compos Mater, 2(1), 120123 (1968).

52. Bowden, P.B. and S. Raha, Formation of micro shear bands in polystyrene and polymethylmethacrylate, Phil Mag, 22(177), 463-482 (1970).

53. Bowden, P.B. The yield behaviour of glassy polymers, in The Physics of Glassy Polymers, Ed. R.N. Haward, 1st Ed., p.279-339 (Applied Science Publishers, London, 1973).

54. Van Melick, H.G.H., L.E. Govaert and H.E.H. Meijer, On the origin of strain hardening in glassy polymers, Polymer, 44(8), 2493-2502 (2003).

55. Pearson, R.A. and A.F. Yee, Toughening mechanisms in elastomer-modified epoxies. 3. The effect of cross-link density, J Mater Sci, 24(7), 2571-2580 (1989).

56. Caddell, R.M., Deformation and fracture of solids. (Prentice-Hall, Englewood Ciffs, New Jersey, 1980).

57. Lee, J. and A.F. Yee, Role of inherent matrix toughness on fracture of glass bead filled epoxies, Polymer, 41, 8375-8385 (2000).

58. Kinloch, A.J. and A.C. Taylor, The toughening of cyanate-ester polymers Part I Physical modification using particles, fibres and woven-mats, J Mater Sci, 37(3), 433-460 (2002).

59. Kinloch, A.J., Adhesion and Adhesives : Science and Technology. (Chapman \& Hall, London, 1987).

60. Norman, D.A. and R.E. Robertson, Rigid-particle toughening of glassy polymers, Polymer, 44(8), 23512362 (2003).

61. Williams, J.G., Particle toughening of polymers by plastic void growth, Compos Sci \& Technol, 70(6), 885-891 (2010).

62. Huang, Y. and A.J. Kinloch, Modelling of the toughening mechanisms in rubber-modified epoxy polymers. Part II: A quantitative description of the microstructure-fracture property relationships, J Mater Sci, 27(10), 2763-2769 (1992).

63. Hsieh, T.H., A.J. Kinloch, K. Masania, J. Sohn Lee, A.C. Taylor and S. Sprenger, Erratum to: The toughness of epoxy polymers and fibre composites modified with rubber microparticles and silica nanoparticles, J Mater Sci, to be published (2010).

64. Sultan, J.N. and F.J. McGarry, Effect of rubber particle size on deformation mechanisms in glassy epoxy, Polym Eng Sci, 13, 29-34 (1973).

65. Guild, F.J. and R.J. Young, A predictive model for particulate-filled composite-materials 1.Hard Particles, J Mater Sci, 24(1), 298-306 (1989).

66. Guild, F.J. and R.J. Young, A predictive model for particulate-filled composite-materials 2.Soft particles, J Mater Sci, 24(1), 2454-2460 (1989).

67. Kinloch, A.J. and R.J. Young, Fracture behaviour of polymers. (Elsevier Applied Sciences, London, 1983).

68. Huang, Y. and A.J. Kinloch, Modelling of the toughening mechanisms in rubber-modified epoxy polymers: Part I: Finite element analysis and studies, J Mater Sci, 27(10), 2753-2762 (1992).

69. Vörös, G. and B. Pukánszky, Stress distribution in particulate filled composites and its effect on micromechanical deformation, J Mater Sci, 30(16), 4171-4178 (1995).

70. Pukánszky, B. and G. Vörös, Stress distribution around inclusions, interaction, and mechanical properties of particulate-filled composites, Polym Compos, 17(3), 384-392 (1996). 
Table 1. The glass transition temperature, $T_{g}$, tensile storage modulus, $E_{r}$, in the rubber plateau region and molecular weight, $M_{c}$, between cross-links for the unmodified epoxy-polymers.

\begin{tabular}{|c|c|c|c|}
\hline Epoxy polymer & $T_{g}\left({ }^{\circ} \mathrm{C}\right)$ & $E_{r}(\mathrm{MPa})$ & $M_{c}(\mathrm{~g} / \mathrm{mol})$ \\
\hline Anhydride-cured DGEBA & 143 & 19.8 & 408 \\
\hline Polyether-amine cured DGEBA/F & 68 & 16.7 & 433 \\
\hline Polyether-amine cured DGEBA & 89 & 16.0 & 464 \\
\hline Amine-cured TGMDA & 186 & 21.3 & 393 \\
\hline
\end{tabular}


Table 2. The properties of the unmodified and silica-nanoparticle filled epoxy-polymers.

\begin{tabular}{|c|c|c|c|c|c|}
\hline Epoxy polymer & $\begin{array}{c}v_{f} \text { of silica } \\
\text { nanoparticles }\end{array}$ & $T_{g}\left({ }^{\circ} \mathrm{C}\right)$ & $E(\mathrm{GPa})$ & $K_{c}(\mathrm{MPa} \sqrt{\mathrm{m}})$ & $G_{c}\left(J / m^{2}\right)$ \\
\hline \multirow{3}{*}{ Anhydride-cured DGEBA } & 0 & $143 \pm$ & $2.96 \pm 0.08$ & $0.51 \pm 0.09$ & $77 \pm 15$ \\
\hline & 0.065 & $140 \pm 2$ & $3.34 \pm 0.06$ & $0.75 \pm 0.02$ & $156 \pm$ \\
\hline & 0.134 & $142 \pm$ & $3.85 \pm 0.11$ & $0.88 \pm 0.06$ & $212 \pm$ \\
\hline \multirow{3}{*}{ Polyether-amine cured DGEBA/F } & 0 & $68 \pm$ & $3.16 \pm 0.07$ & $0.78 \pm 0.07$ & $184 \pm 23$ \\
\hline & 0.064 & $68 \pm 1$ & $3.43 \pm 0.1$ & $1.40 \pm 0.06$ & $444 \pm 37$ \\
\hline & 0.133 & $69 \pm$ & $3.48 \pm 0.07$ & $1.76 \pm 0.16$ & $702 \pm 125$ \\
\hline \multirow{3}{*}{ Polyether-amine cured DGEBA } & 0 & $89 \pm 0$ & $2.94 \pm 0.11$ & $0.73 \pm 0.13$ & $163 \pm 55$ \\
\hline & 0.066 & $89 \pm 1$ & $3.24 \pm 0.12$ & $1.38 \pm 0.06$ & $490 \pm 72$ \\
\hline & 0.138 & $87 \pm$ & $3.44 \pm 0.36$ & $1.45 \pm 0.12$ & $616 \pm 109$ \\
\hline \multirow{3}{*}{ Amine-cured TGMDA } & 0 & $186 \pm 2$ & $3.14 \pm 0.06$ & $0.51 \pm 0.06$ & $70 \pm 21$ \\
\hline & 0.066 & $184 \pm$ & $3.55 \pm 0.03$ & $0.71 \pm 0.05$ & $114 \pm 13$ \\
\hline & 0.137 & $186 \pm 0$ & $3.97 \pm 0.01$ & $0.88 \pm 0.10$ & $172 \pm 18$ \\
\hline
\end{tabular}


Table 3. Values of the true tensile yield stress, $\sigma_{y}$, true compressive yield stress, $\sigma_{y c}$, and true compressive fracture strain, $\gamma_{f}$, for the unmodified epoxy-polymers.

\begin{tabular}{|c|c|c|c|}
\hline Epoxy Polymer & $\begin{array}{c}\sigma_{y} \\
(\mathrm{MPa})\end{array}$ & $\begin{array}{c}\sigma_{y c} \\
(\mathrm{MPa})\end{array}$ & $\gamma_{f}$ \\
\hline Anhydride-cured DGEBA & 88 & 120 & 0.75 \\
\hline Polyether-amine cured DGEBA/F & 82 & 101 & 1.06 \\
\hline Polyether-amine cured DGEBA & 67 & 96 & 0.86 \\
\hline Amine-cured TGMDA & $111^{*}$ & 140 & 0.76 \\
\hline
\end{tabular}

( ${ }^{*}$ A yield stress could not be recorded in tension and hence was calculated using Eq. (14).) 
Table 4. Predicted fracture energies compared to the measured fracture energies for the epoxy polymers.

\begin{tabular}{|c|c|c|c|c|c|}
\hline Epoxy polymer & $\begin{array}{c}v_{f} \text { of silica } \\
\text { nanoparticles }\end{array}$ & $\begin{array}{c}\Delta G_{s} \\
\left(\mathrm{~J} / \mathrm{m}^{2}\right)\end{array}$ & $\begin{array}{c}\Delta G_{V} \\
\left(\mathrm{~J} / \mathrm{m}^{2}\right)\end{array}$ & $\begin{array}{c}G_{c} \\
\text { (predicted) } \\
\left(\mathrm{J} / \mathrm{m}^{2}\right)\end{array}$ & $\begin{array}{c}\mathrm{G}_{c} \\
\text { (measured) } \\
\left(\mathrm{J} / \mathrm{m}^{2}\right)\end{array}$ \\
\hline \multirow{3}{*}{ Anhydride-cured DGEBA } & 0 & - & - & - & 77 \\
\hline & 0.065 & 46 & 39 & 162 & 156 \\
\hline & 0.134 & 79 & 64 & 220 & 212 \\
\hline \multirow{3}{*}{ Polyether-amine cured DGEBA/F } & 0 & - & - & - & 184 \\
\hline & 0.064 & 144 & 160 & 488 & 444 \\
\hline & 0.133 & 204 & 334 & 722 & 702 \\
\hline \multirow{3}{*}{ Polyether-amine cured DGEBA } & 0 & - & - & - & 163 \\
\hline & 0.066 & 225 & 0 & 388 & 490 \\
\hline & 0.138 & 319 & 0 & 482 & 616 \\
\hline \multirow{3}{*}{ Amine-cured TGMDA } & 0 & - & - & - & 70 \\
\hline & 0.066 & 34 & 0 & 104 & 114 \\
\hline & 0.137 & 48 & 0 & 118 & 172 \\
\hline
\end{tabular}




\section{Figure Caption List}

Figure 1. AFM phase images of the microstructure of the polyether-amine cured DGEBA epoxy polymer:
(a)
Unmodified.
(b) and (c)
$0.138 v_{f}$ of silica nanoparticles.

Figure 2. The normalised Young's modulus versus volume fraction, $v_{f}$, of silica nanoparticles for the different epoxy polymers.

Figure 3. True-stress versus true-strain relationships for the unmodified epoxy-polymers from the planestrain compression tests.

Figure 4. Transmission optical micrographs, using polarised light, of polished sections from the unmodified epoxy-polymers which were loaded to within the strain-softening region, see Fig. 3. (Compressive loads applied to the top and bottom surfaces of the sections.)

Figure 5. The normalised fracture energy versus volume fraction, $v_{f}$, of silica nanoparticles for the different epoxy polymers.

Figure 6. Transmission optical micrograph from the (non-propagating) crack-tip region of the DN4PB test specimens showing the plane-stress region taken between crossed-polarisers. For the anhydride-cured DGEBA epoxy polymer containing a $v_{f}=0.065$ of silica nanoparticles.

Figure 7. High-resolution FEG-SEM micrographs of the fracture surface of (a) an unmodified polyetheramine cured DGEBA/F epoxy polymer; and (b) and (c) the epoxy polymer containing a $v_{f}=0.133$ of silica nanoparticles. (Some of the voids around the silica nanoparticles are circled.)

Figure 8. Normalised true compressive yield stress versus volume fraction, $v_{f}$, of silica nanoparticles for the different epoxy polymers. (The lines are from the theoretical work of and Vörös and Pukánszky [69, 70] and the values of the proportionality constant, $k$, for interfacial stress transfer are given. The value of $k$ directly reflects the level of silica-nanoparticle/epoxy-polymer interfacial adhesion.) 


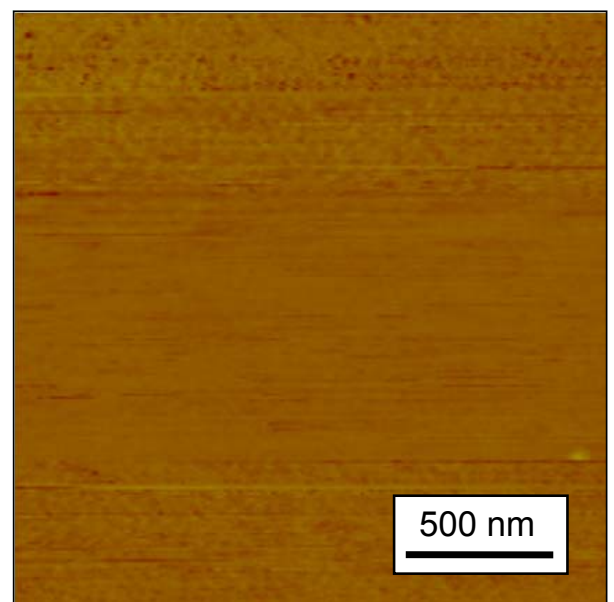

(a) Unmodified

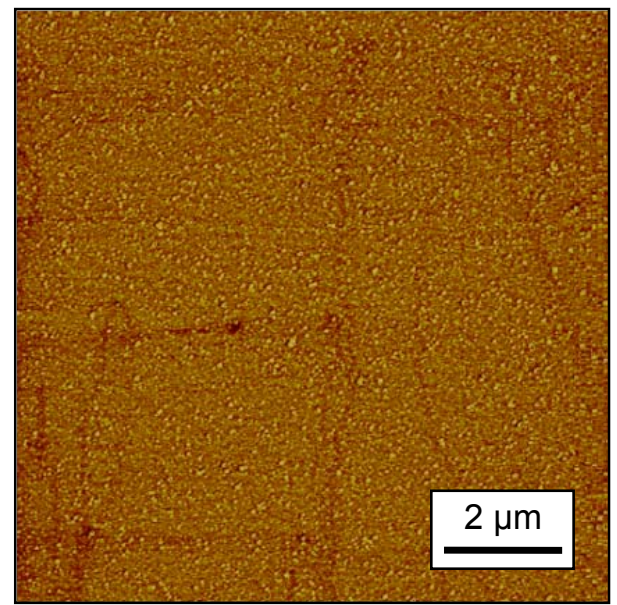

(b) $0.138 v_{f}$ of silica nanoparticles

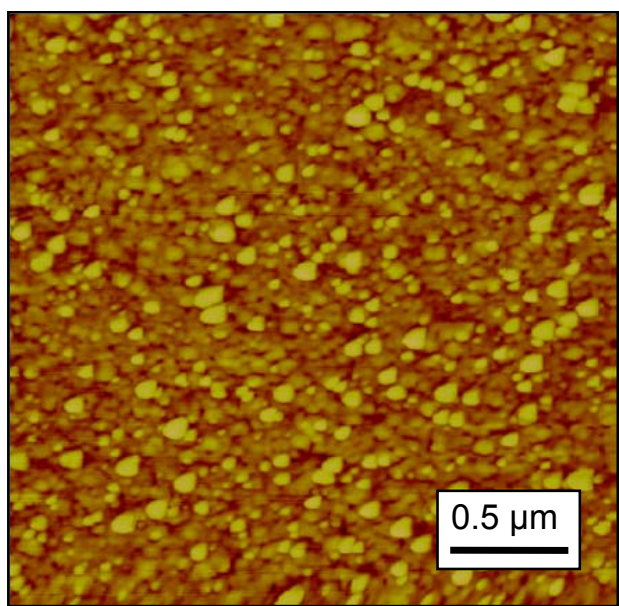

(c) $0.138 v_{f}$ of silica nanoparticles 
Figure 1. AFM phase images of the microstructure of the polyether-amine cured DGEBA epoxy polymer:

(a) Unmodified;

(b) and (c) $0.138 v_{f}$ of silica nanoparticles. 


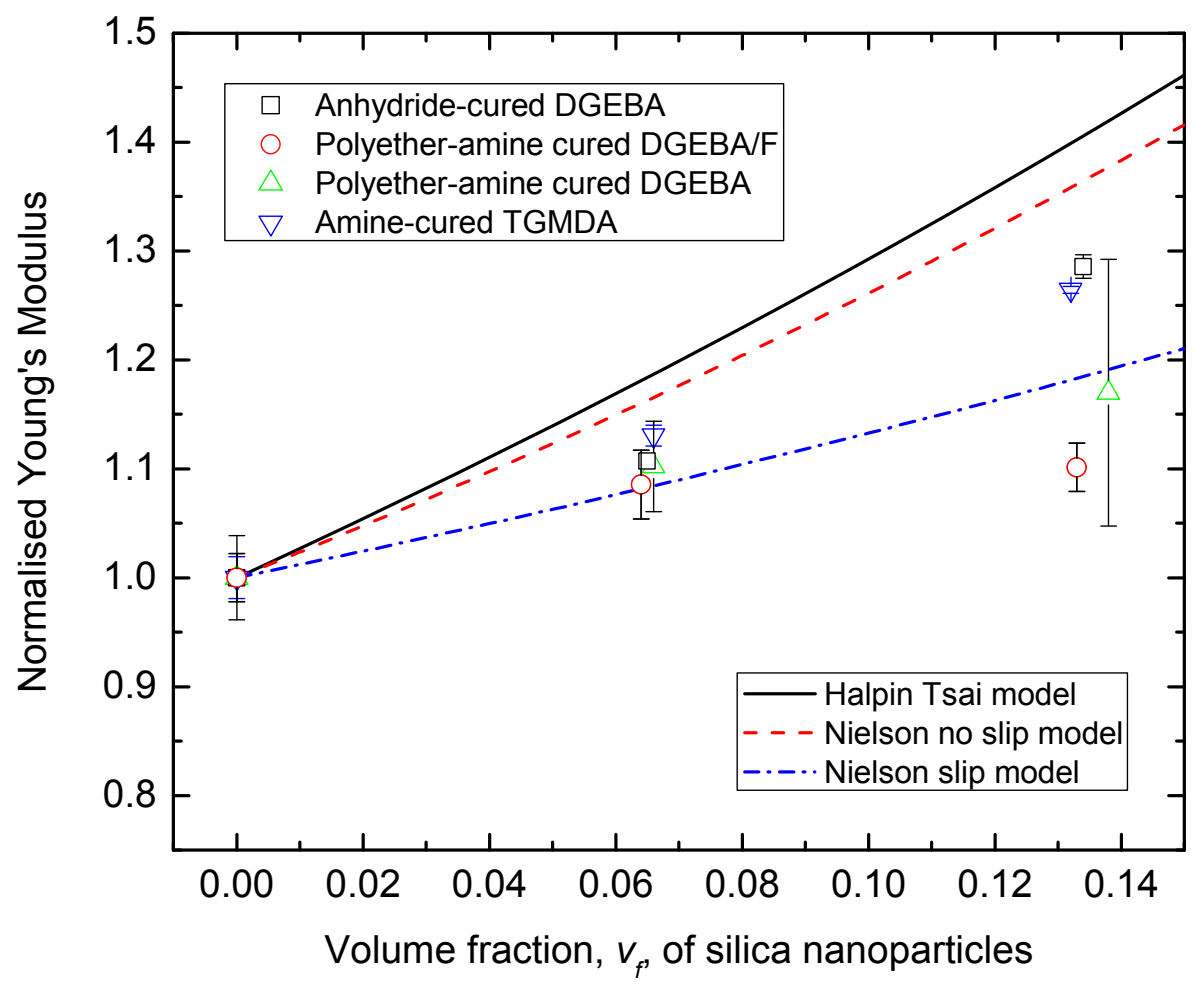

Figure 2. The normalised Young's modulus versus volume fraction, $v_{f}$, of silica nanoparticles for the different epoxy polymers. 


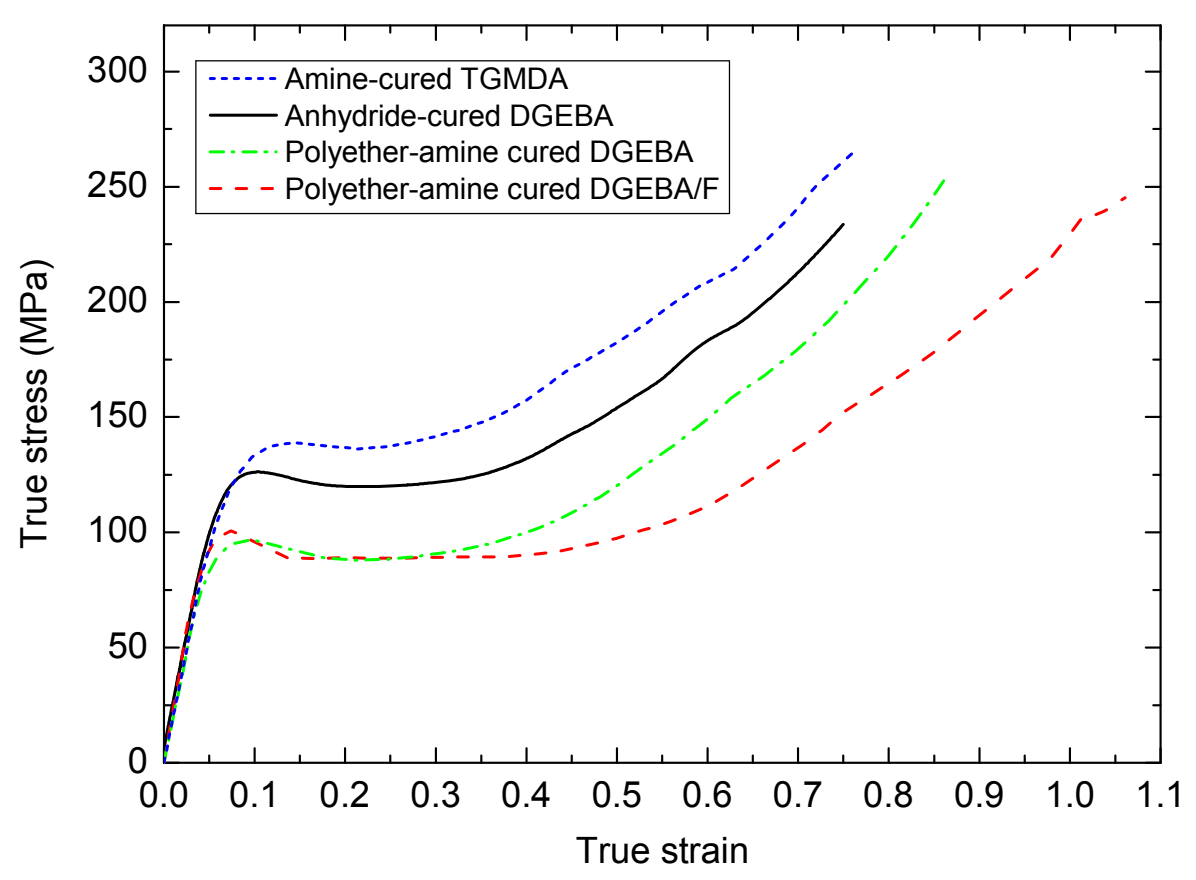

Figure 3. True-stress versus true-strain relationships for the unmodified epoxy-polymers from the planestrain compression tests. 


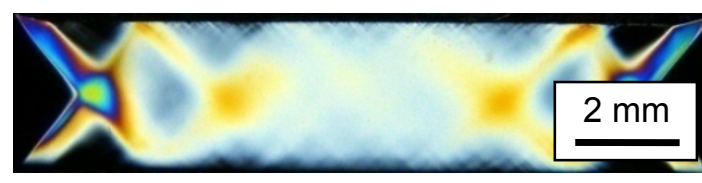

Anhydride-cured DGEBA

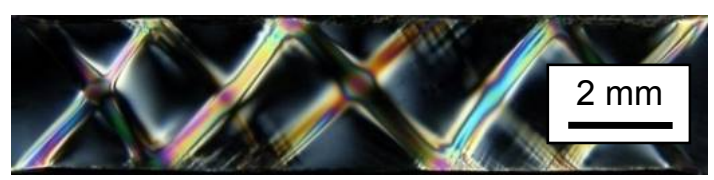

Polyether-amine cured DGEBA/F

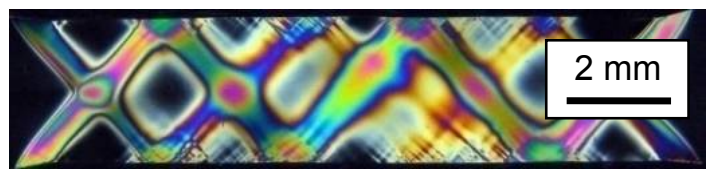

Polyether-amine cured DGEBA

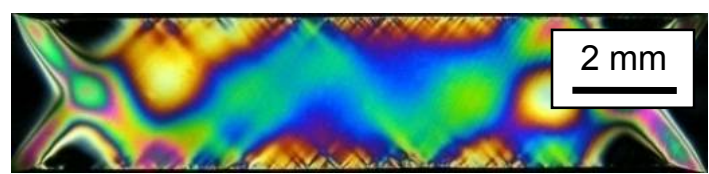

Amine-cured TGMDA

Figure 4. Transmission optical micrographs, using polarised light, of polished sections from the unmodified epoxy-polymers which were loaded to within the strain-softening region, see Fig. 3. (Compressive loads applied to the top and bottom surfaces of the sections.) 


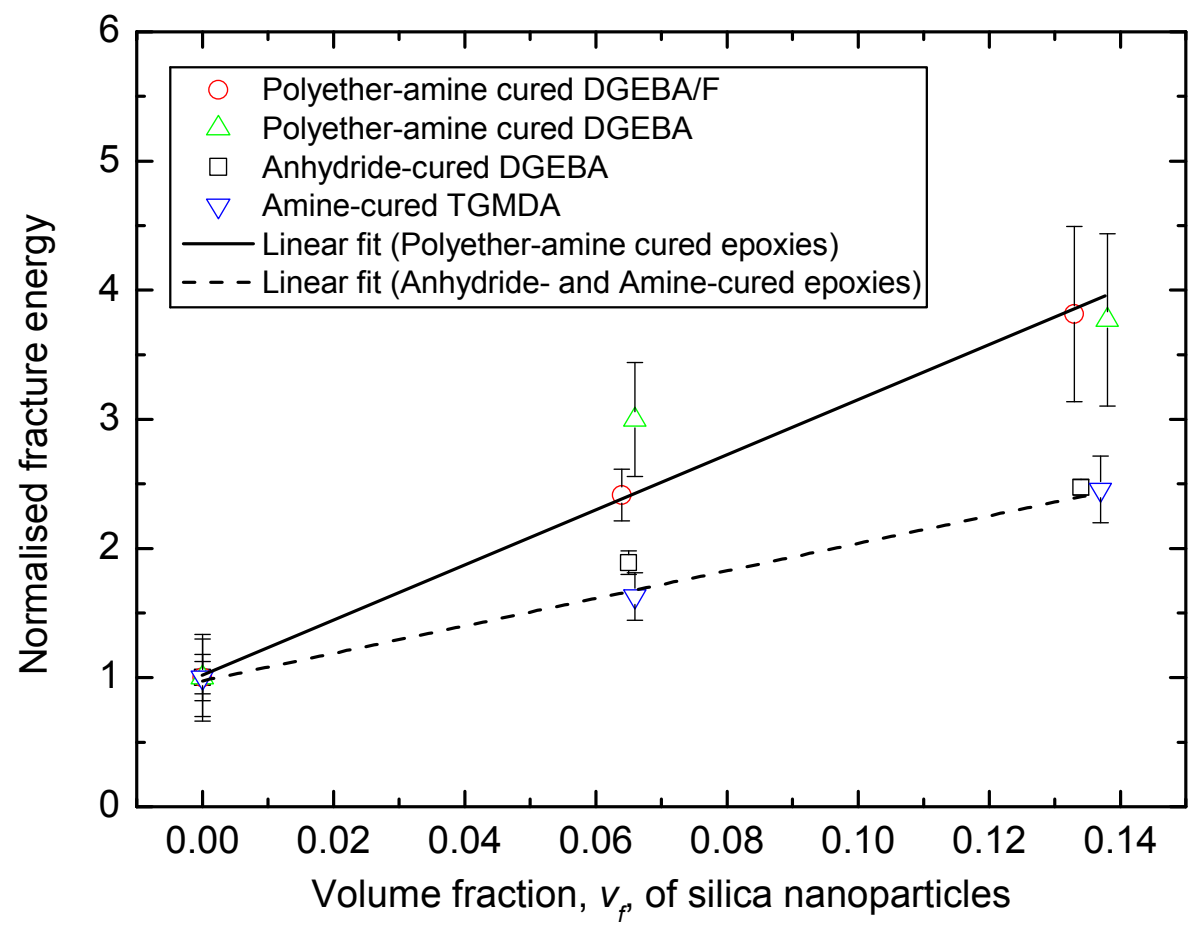

Figure 5. The normalised fracture energy versus volume fraction, $v_{f}$, of silica nanoparticles for the different epoxy polymers. 


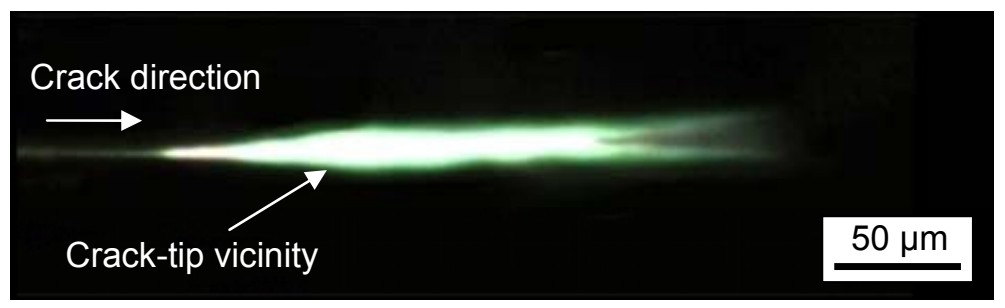

Figure 6. Transmission optical micrograph from the (non-propagating) crack-tip region of the DN4PB test specimens showing the plane-stress region taken between crossed-polarisers. For the anhydride-cured DGEBA epoxy polymer containing a $v_{f}=0.065$ of silica nanoparticles. 
(a)

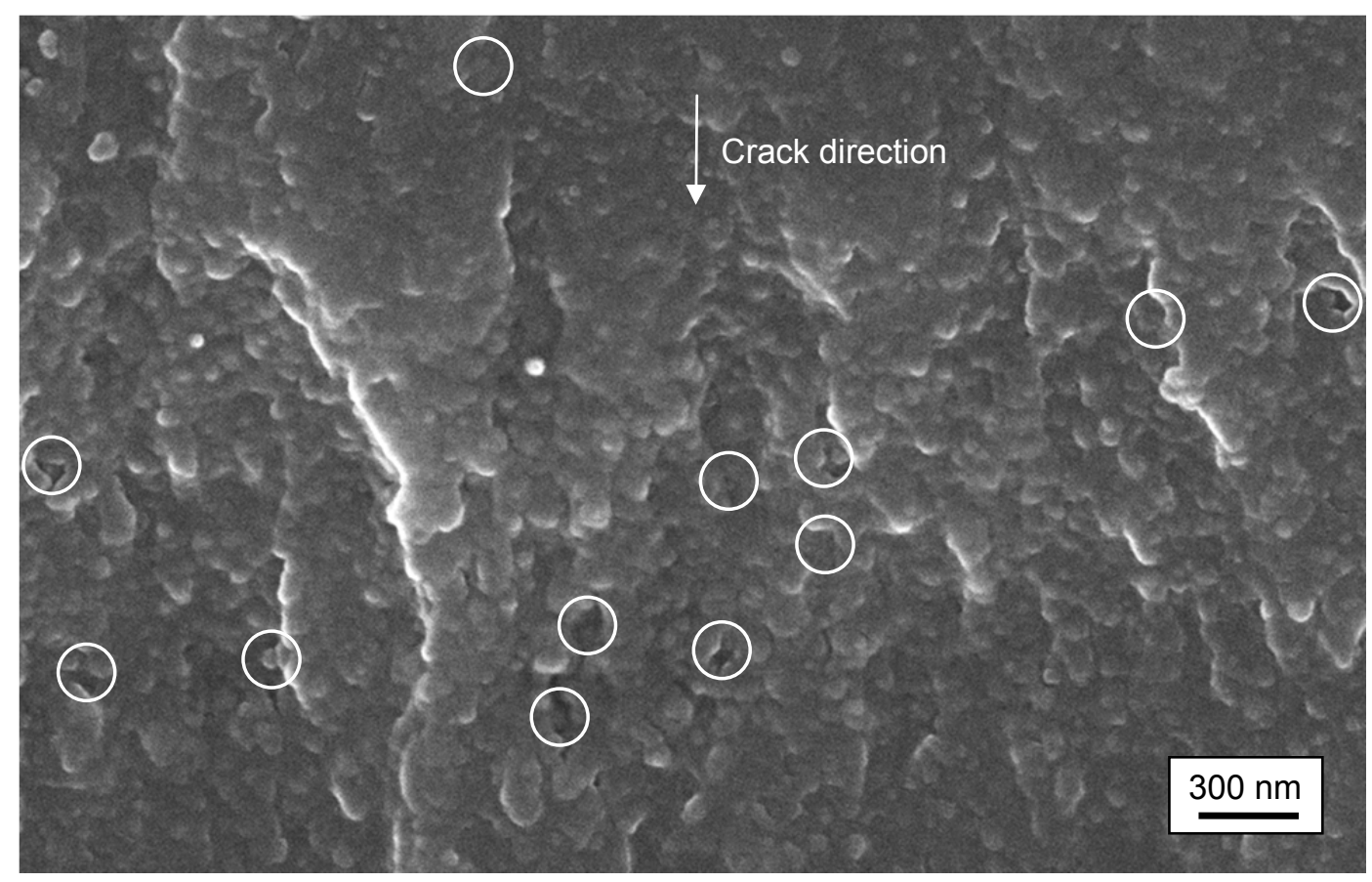

(b)

Figure 7. High-resolution FEG-SEM micrographs of the fracture surface of (a) an unmodified polyetheramine cured DGEBA/F epoxy polymer; and (b) and (c) the epoxy polymer containing a $v_{f}=0.133$ of silica nanoparticles. (Some of the voids around the silica nanoparticles are circled.) 


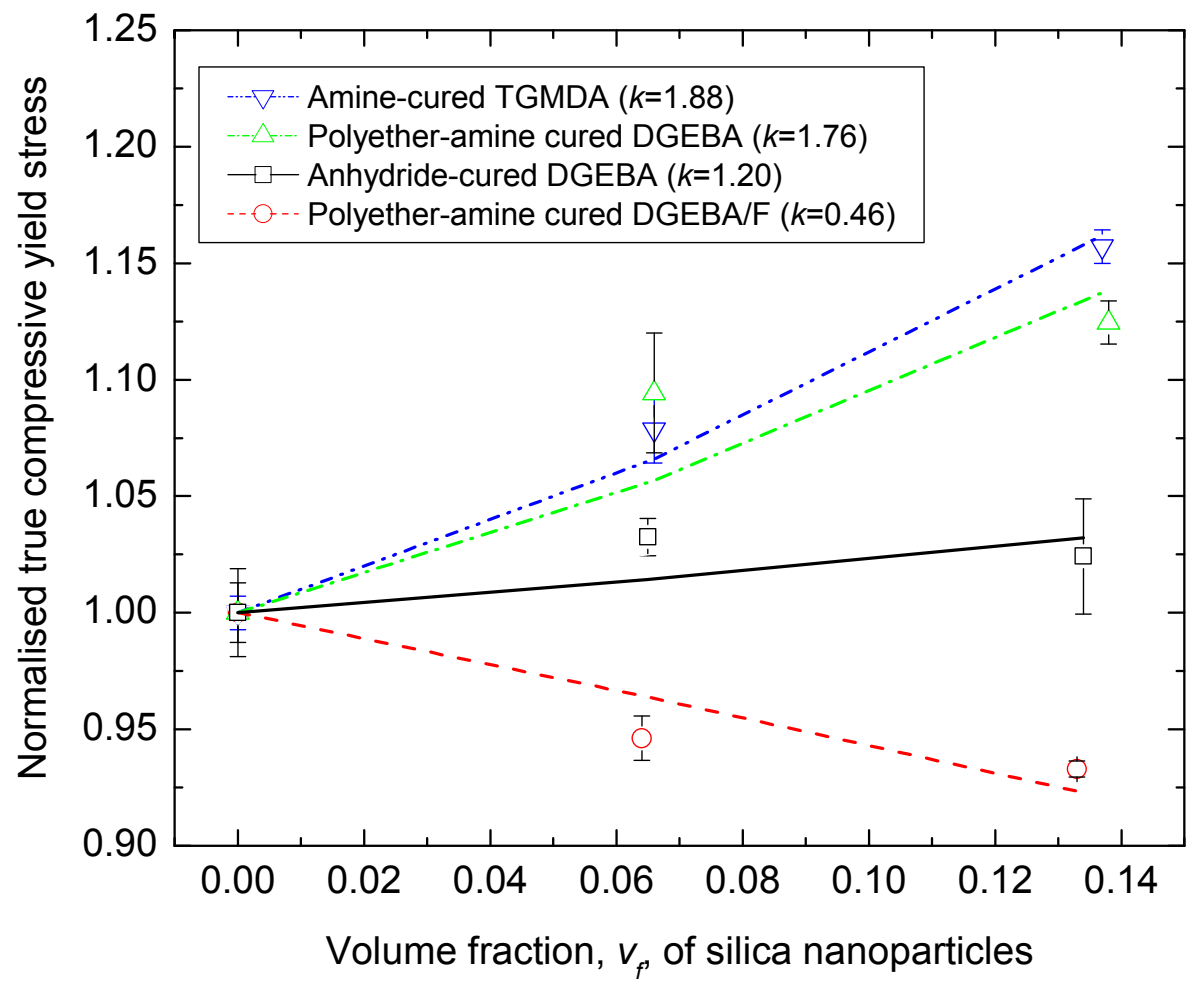

Figure 8. Normalised true compressive yield stress versus volume fraction, $v_{f}$, of silica nanoparticles for the different epoxy polymers. (The lines are from the theoretical work of and Vörös and Pukánszky [69, 70] and the values of the proportionality constant, $k$, for interfacial stress transfer are given. The value of $k$ directly reflects the level of silica-nanoparticle/epoxy-polymer interfacial adhesion.) 